\title{
Development of Silica Nanoparticle from Corn Cob Ash
}

\author{
Elvis A. Okoronkwo ${ }^{*}$, Patrick Ehi Imoisili1,2, Smart A. Olubayode ${ }^{2,3}$, Samuel 0. O. Olusunle ${ }^{2}$ \\ ${ }^{1}$ Chemistry Department, Federal University of Technology, Akure, Nigeria \\ ${ }^{2}$ Engineering Materials Development Institute, Akure, Nigeria \\ ${ }^{3}$ Department of Civil Engineering, University of Agriculture, Abeokuta, Nigeria \\ Email: *afamex@yahoo.com
}

Received 17 December 2015; accepted 16 May 2016; published 19 May 2016

Copyright (C) 2016 by authors and Scientific Research Publishing Inc.

This work is licensed under the Creative Commons Attribution International License (CC BY).

http://creativecommons.org/licenses/by/4.0/

(c) () Open Access

\begin{abstract}
Silica from corn cob ash (CCA) was extracted via sol-gel, and nanostructured with templating concept, these resulted in silica nanoparticle. Silica and mineral contents of CCA were determined by X-ray fluorescence (XRF). X-ray diffraction (XRD) patterns revealed amorphous nature of extracted silica. Fourier transform infrared (FTIR) data indicated the presence of siloxane and silanol groups. X-ray diffraction (XRD) of nanostrurtured silica reviled average particle size of $54 \mathbf{~ n m}$, Scanning electron microscopy/energy dispersive X-ray spectroscopy (SEM/EDS) study indicates the particles to possess disorder morphology with the particle attached to each other through grain boundary to form agglomerated structure, and SEM analysis shows that particle size varies from $44 \mathrm{~nm}-98 \mathrm{~nm}$ in diameter, with an average diameter of $55 \mathrm{~nm}$. EDS spectrum confirms $\mathrm{SiO}_{2}$.
\end{abstract}

\section{Keywords}

Corn Cob, Silica, Sol-Gel, Nanoparticle, X-Ray Diffraction

\section{Introduction}

Silica has been successfully extracted from different agricultural materials like rice husk [1]-[4], sugar cane Bagasse [5] [6], coffee husk [7], wheat husk [8] and corn cob [9] [10].

One of the most important techniques used to prepare nanosilica is the sol-gel process. Nanofillers synthesised using this method are reported to have a distinct spherical shape with a narrow size distribution that is useful for dental applications [11] [12]. The extremely small nanoparticle size provides low visual opacity in un-pigmented dental composites, which allows researchers to prepare a wide variety of shades and opacities of

*Corresponding author.

How to cite this paper: Okoronkwo, E.A., Imoisili, P.E., Olubayode, S.A. and Olusunle, S.O.O. (2016) Development of Silica Nanoparticle from Corn Cob Ash. Advances in Nanoparticles, 5, 135-139. http://dx.doi.org/10.4236/anp.2016.52015 
dental composites and thus providing highly aesthetic restorations. Furthermore, spherically shaped nanosilica particles provide superior polishability [13] and tend to distribute mechanical stress more uniformly than irregularly shaped particles, which lead to improved mechanical properties [14].

Synthesis of nano $\mathrm{SiO}_{2}$ is currently of great interest because it is a basic raw material that is widely used in electronics and polymer material industries. Recently, Mohanraj et al. (2012) [9] prepared and characterized nano $\mathrm{SiO}_{2}$ from corn cob ash by precipitation method. Using the sol-gel technique has a benefit of producing valuable silica particles at lower cost.

The objective of this present work is to extract silica from corn cob by sol-gel method and nanostructured the extracted silica with templating concept using hexadecyl trimethyly ammonium bromide (CTAB) as template. The ash extracted silica and nanosilica was characterized using X-ray fluorescence (XRF), X-ray diffraction (XRD), Fourier transform infrared spectroscopy (FTIR) and Scanning Electron Microscopy/Energy Dispersive $\mathrm{X}$-ray spectroscopy (SEM/EDX).

\section{Materials and Methods}

Corn cob, was obtained from south western Nigeria after the harvest season, the corn cobs was washed and sun dried. The combustion were carried out at $650^{\circ} \mathrm{C}$ for 3 hours at a heating rate of $10^{\circ} \mathrm{C} / \mathrm{min}$ in a muffle furnace, and left over night to cool in the furnace. Silica was extracted from Corn Cob Ash, (CCA) adapting the sol-gel method as previously reported [1] [10]. To nanostructured of extracted silica, modify method suggested by Sayari et al. (2001) was adopted [15]. Hexadecyl trimethyly ammonium bromide (CTAB) was dissolved in distilled water and stirred for 5 mins to obtain a transparent homogenous solution. $\mathrm{NH}_{4} \mathrm{OH}$ was added with continuous stirring for 10 mins, after which extracted silica was slowly added and allowed to age under stirring at room temperature for a total of $20 \mathrm{hrs}$, after which the silica was harvested and dried in the oven for $24 \mathrm{hr}$ at $105^{\circ} \mathrm{C}$, there after, the samples were calcined in a muffle furnace at $550^{\circ} \mathrm{C}$.

\section{Results and Discussions}

The corn cod ash, extracted and nano silica was subjected to XRD, XRF, FTIR and SEM. The X-ray diffraction (XRD) was monitored using X-ray diffractometer GBC EMMA, $\mathrm{CuK} \alpha$ radiation using an acceleration voltage of $25 \mathrm{kV}$ and current of $400 \mu \mathrm{A}$. The diffraction angle was scanned from $15^{\circ}$ to $60^{\circ} 2 \theta$, at a rate of $4.00 \% \mathrm{~min}$. The quantitative analysis of chemical components of corn cob ash and silica extract was done using X-Ray fluorescence (XRF). FTIR spectral were recorded in the range of $4000-350 \mathrm{~cm}^{-1}$; morphology was monitored using Scanning electron microscopy/energy dispersive X-ray spectroscopy (SEM/EDX).

Different stages of Silica powder extraction from corn cob ash are shown in Figure 1. The major chemical groups present in the extracted silica were identified by FTIR spectral as shown in Figure 2. The broad band at $3440 \mathrm{~cm}^{-1}$ to $3490 \mathrm{~cm}^{-1}$ was due to the stretching vibration of the O-H bond from the silanol groups (Si-OH) and is due to the adsorbed water molecules on the silica surface [9]-[11], the band at $1075 \mathrm{~cm}^{-1}$ to $1098 \mathrm{~cm}^{-1}$ is due to the Si-O-Si asymmetric stretching vibration [9]-[11], while the band at $791 \mathrm{~cm}^{-1}$ to $806 \mathrm{~cm}^{-1}$ has been assigned to the network Si-O-Si symmetric bond stretching vibration, and the band at $461 \mathrm{~cm}^{-1}$ to $476 \mathrm{~cm}^{-1}$ is associated with a network O-Si-O bending vibration modes [11].

The chemical composition of corn cob ash, and silica extract analyse by X-ray fluorescence (XRF) are shown in Table 1. It was however observed that minimal impurities were still present after extraction.

The X-ray diffractogram of corn cob ash, extracted silica and nano silica are shown in Figure 3. The strong peak notice at $20.9^{\circ}, 26.6^{\circ}$ in Figure 3(a) indicates the present of silica in the ash.

The broad X-ray diffraction pattern in Figure 3(b), is typical of amorphous solids, it shows that the extracted silica is predominantly amorphous [1] [9] [10]. Diffraction peak at theta $=22$ degree confirms the formation of amorphous silica, in general, it has been reported that Diffraction broad peak at theta $=22$ degree indicates amorphous silica along with some crystalline silica [8]-[10]. Figure 3(c), shows the X-ray diffractogram of nanostructured silica, the particle size of the silica was determined from the X-ray diffraction data using Debye Sherrer's formula,

$$
D=0.89 \lambda / \beta \cos \theta
$$

where, $D$ is the particle size , $\lambda$ is the wavelength of the incident X-ray beam, $\beta$ is the full width at half maximum of the $\mathrm{X}$-ray diffraction peaks and $\theta$ is Bragg angle of $\mathrm{X}$-ray diffraction peak. The average particle size of 


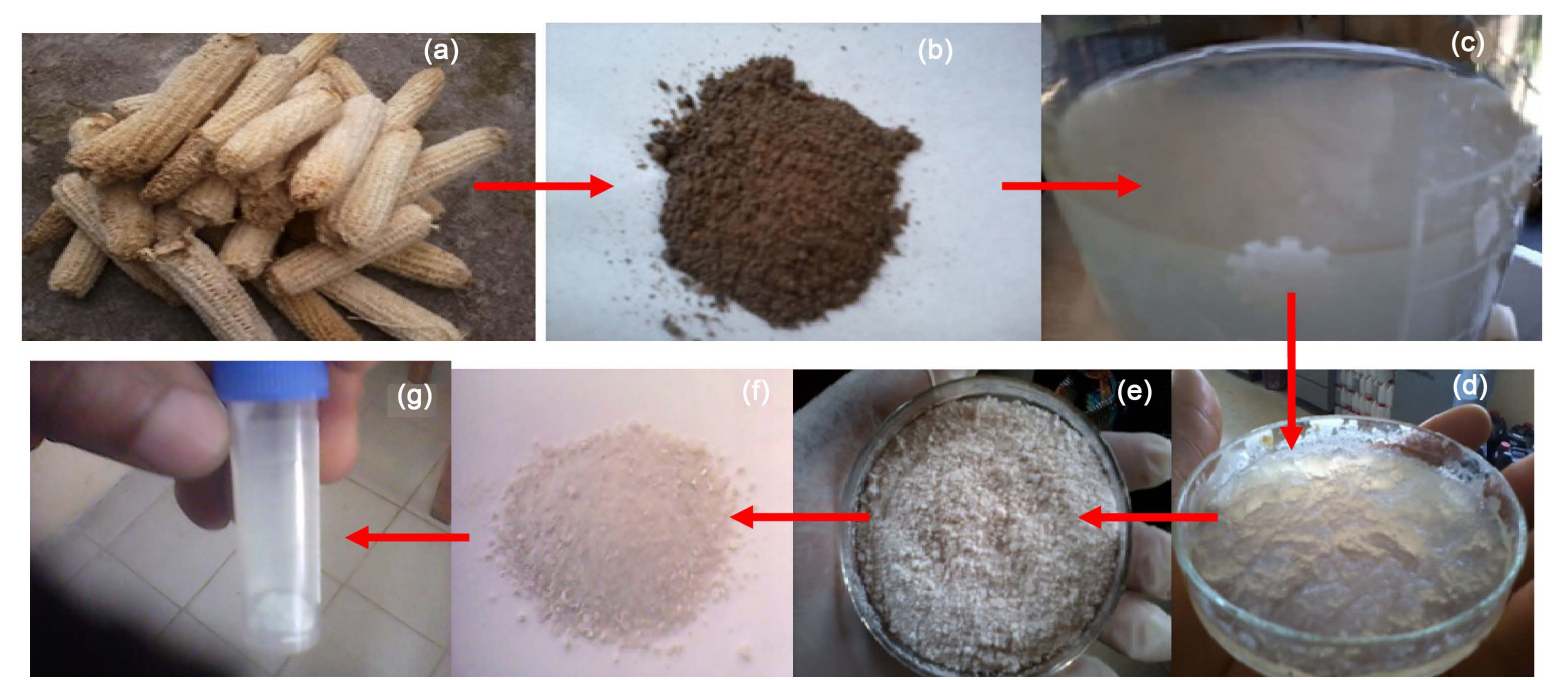

Figure 1. Photos of silica from corn cob. (a) Corn cob; (b) Corn cob ash; (c) Sodium silicate gel (d) Silica aqua gel (e) Silica xerogel (f) Extracted amorphous silica (g) Nano silica.

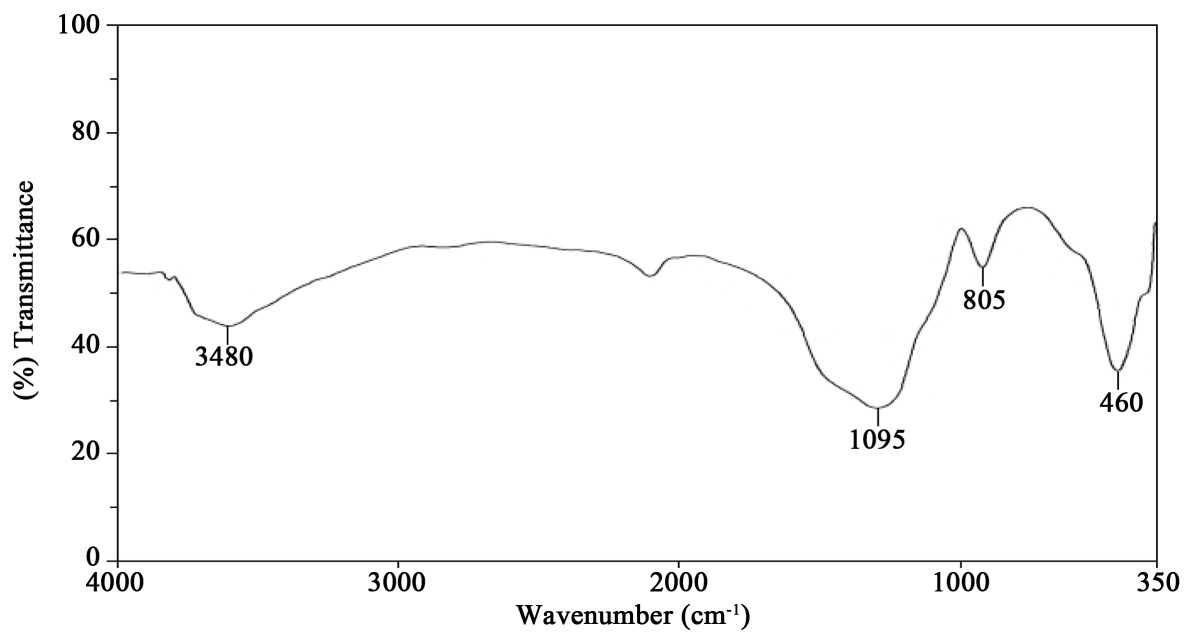

Figure 2. Fourier transform infrared spectra of silica produced from CCA.

Table 1. Chemical composition of corn cob ash and silica extracted.

\begin{tabular}{ccc}
\hline Constituent & Corn cob ash (wt \%) & After extraction (wt \%) \\
\hline $\mathrm{SiO}_{2}$ & 47.78 & 98.77 \\
$\mathrm{Al}_{2} \mathrm{O}_{3}$ & 9.40 & 0.00 \\
$\mathrm{Fe}_{2} \mathrm{O}_{3}$ & 8.31 & 0.00 \\
$\mathrm{CaO}$ & 16.70 & 0.00 \\
$\mathrm{MgO}$ & 7.80 & 0.00 \\
$\mathrm{Mn}_{2} \mathrm{O}_{3}$ & 2.70 & 0.00 \\
$\mathrm{~K}_{2} \mathrm{O}$ & 5.42 & 0.74 \\
$\mathrm{Na}_{2} \mathrm{O}$ & 1.89 & 0.49 \\
\hline
\end{tabular}


the prepared silica is found to be $54 \mathrm{~nm}$.

The SEM image and EDS spectral are shown in Figure 4. Scanning Probe Image Processor (SPIP 6.0.13) analysis reveals that particle size varies from $44 \mathrm{~nm}-98 \mathrm{~nm}$ in diameter, with an average diameter of $55 \mathrm{~nm}$. EDS spectral as shown in Figure 4(b), reveals a strong intensity of $\mathrm{Si}$ alone in the spectrum which confirms predominant of silica in the sample and some traces of impurities.

\section{Conclusion}

This study revealed that amorphous silica, with minimal mineral contaminants could be produced from corn cob using the sol-gel method. XRD analysis reveals the amorphous nature of the silica; Fourier transform infrared (FTIR) data indicate the presence of siloxane and silanol groups. Nano-structuring of extracted silica using templating concept has been successful, SEM analysis using Scanning Probe Image Processor (SPIP 6.0.13) revealed that 7855 particle was detected in the SEM image, and particle size varies from $44 \mathrm{~nm}$ - $58 \mathrm{~nm}$ in diameter, with an average diameter of $51 \mathrm{~nm}$, this is similar to that obtain by Mohanraj et al. (2012) [9] who reported a particle size of 30 - $50 \mathrm{~nm}$ using precipitation method to obtain Nano silica. Thus silica nano particle can be obtain from corn cob ash and can be useful for many industrial applications.

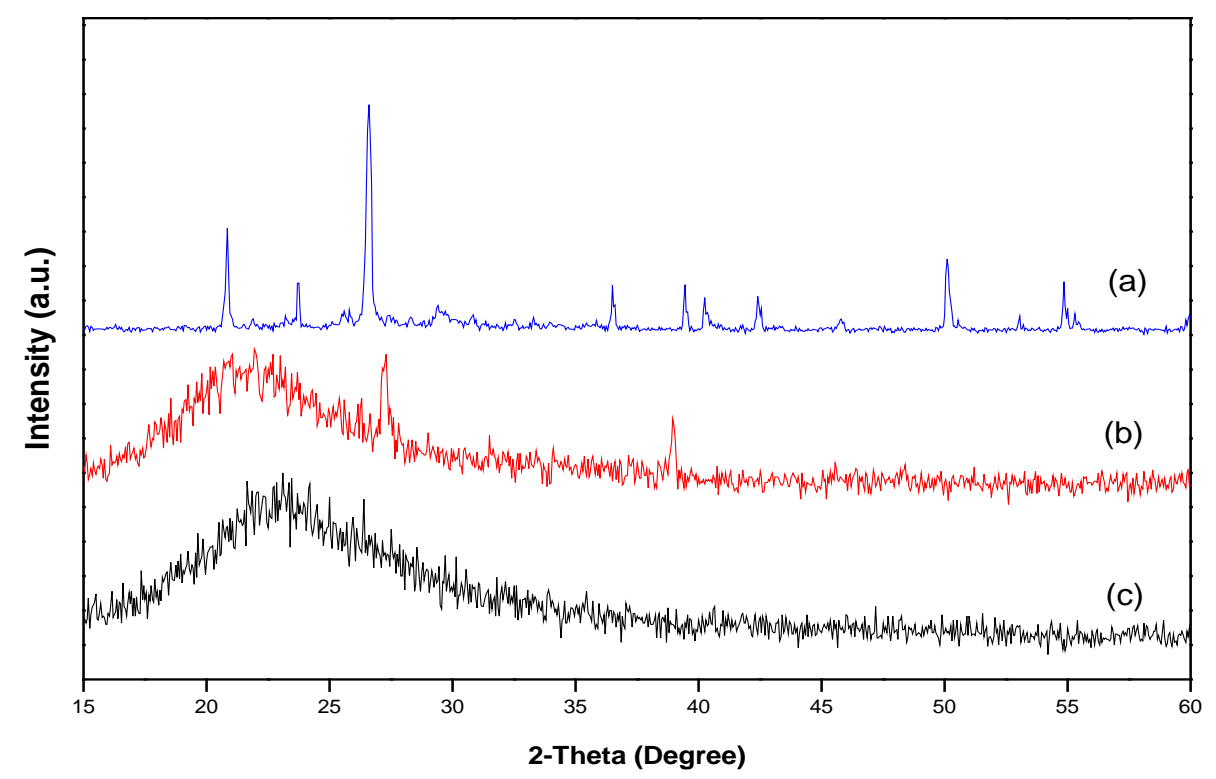

Figure 3. XRD pattern of (a) Corn con ash; (b) extracted silica and (c) Nano silica.

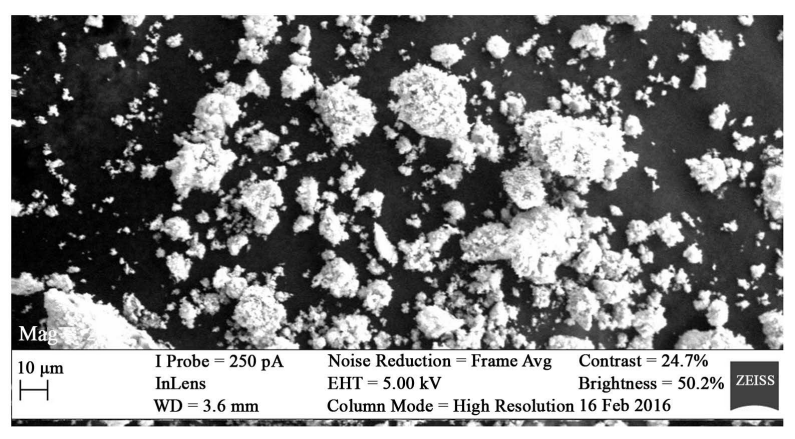

(a)

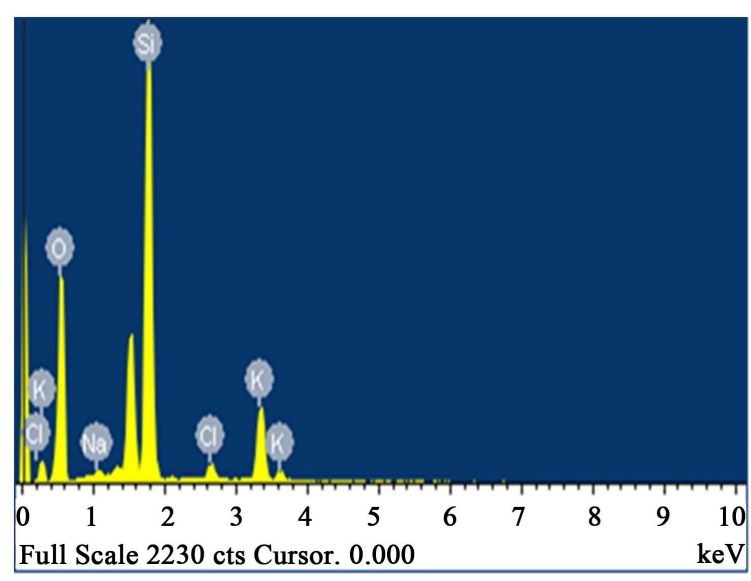

(b)

Figure 4. SEM image of (a) Nano-structured silica and (b) EDS spectrum. 


\section{Acknowledgements}

The contribution of Adebayo Emmanuel of Manitoba University Canada, in carrying out XRD and SEM analysis is greatly appreciated

\section{References}

[1] Kamath, S.R. and Proctor, A. (1998) Silica Gel from Rice Husk Ash: Preparation and Characterization. Cereal Chemistry, 75, 484-487. http://dx.doi.org/10.1094/CCHEM.1998.75.4.484

[2] Polska, K. and Radzki, S. (2008) Spectral and AFM Characterization of Trimethylammoniophenyl-Porphyrin and Concanavalin A Associate in Solution and Monolithic $\mathrm{SiO}_{2}$ Gels Obtained by the Sol-Gel Method. Optical Materials, 30, 1644-1654. http://dx.doi.org/10.1016/j.optmat.2007.10.010

[3] Yalcin, N. and Sevinc, V. (2001) Studies on Silica Obtained from Rice Husk. Ceramics International, 27, $219-224$. http://dx.doi.org/10.1016/S0272-8842(00)00068-7

[4] Sidheswaran, P. and Bhat, A.N. (1996) Recovery of Amorphous Silica in Pure Form from Rice Husk. Transactions of the Indian Ceramic Society, 55, 93-96. http://dx.doi.org/10.1080/0371750X.1996.10804761

[5] Affandi, S., Setyawan, H., Winardi, S., Purwanto, A. and Balgis, R. (2009) A Facile Method for the Production of High Purity Silica Xerogels from Bagasse Ash. J. Adv. Powder Tech., 20, 468-472.

[6] Worathanakul, P., Payubnop, W. and Muangpet, A. (2009) Characterization for Post Treatment Effect of Bagasse Ash for Silica Extraction. World Academy of Science, Engineering and Technology, 56.

[7] Espindola-Gonzalez, A., Martinez-Hernadez, A.L., Angeles-Chavez, C., Castano, V.M. and Velasco-Santos, C. (2010) Novel Crystalline $\mathrm{SiO}_{2}$ Nanoparticles via Annelids Bioprocessing of Agro-Industrial Wastes. Nanoscale Research Letters, 11671, 9654-9656. http://dx.doi.org/10.1007/s11671-010-9654-6

[8] Javed, S.H., Shah, F.H. and Manasha, M. (2011) Extraction of Amorphous Silica from Wheat Husk Using kmno4. JFET, 18, 39-46

[9] Mohanraj, K., Kannan, S., Barathan, S. and Sivakumar, G. (2012) Preparation and Characterization of $\mathrm{Nano} \mathrm{Sio}_{2}$ from Corn Cob Ash by Precipitation Method. Optoelectronics and Advanced Materials-Rapid Communications, 6, 394397.

[10] Okoronkwo, E.A., Imoisili, P.E. and Olusunle, S.O.O. (2013) Extraction and Characterization of Amorphous Silica from Corn Cob Ash by Sol-Gel Method. Chemistry and Materials Research, 3, 68-72.

[11] Nirschl, H. (2003) Nanoscale Particles in Medical Products. Advanced Engineering Materials, 5, 556-559. http://dx.doi.org/10.1002/adem.200310100

[12] Jafarzadeh, M., Rahman, I.A. and Sipaut, C.S. (2009) Synthesis of Silica Nanoparticles by Modified Sol-Gel Process: The Effect of Mixing Modes of the Reactants and Drying Techniques. Journal of Sol-Gel Science and Technology, 50, 328-336. http://dx.doi.org/10.1007/s10971-009-1958-6

[13] Rüttermann, S., Wandrey, C., Raab, W.H.M. and Janda, R. (2008) Novel Nano-Particles as Fillers for an Experimental Resin-Based Restorative Material. Acta Biomaterialia, 4, 1846-1853. http://dx.doi.org/10.1016/j.actbio.2008.06.006

[14] Tian, M., Gao, Y., Liu, Y., Liao, Y., Hedin, N.E. and Fong, H. (2008) Fabrication and Evaluation of BisGMA/TEGDMA Dental Resins/Composites Containing Nano Fibrillar Silicate. Dental Materials, 24, 235-243. http://dx.doi.org/10.1016/j.dental.2007.05.002

[15] Sayari, A. and Hamoudi, S. (2001) Periodic Mesoporous Silica Based Organic Inorganic Nanocomposite Materials. Chemistry of Materials, 13, 3151-3168. http://dx.doi.org/10.1021/cm0110391 